\title{
Occupational Burnout: A Comparison of Field Research of General and Psychiatric Hospitals in Greece after the Financial Crisis
}

\author{
Aspasia Goula, Georgia Koufioti, Athanasios Kounios, Anastasios Sepetis \\ Postgraduate Program in Health and Social Care Management, Department of Business Administration, University of West \\ Attica, Egaleo, Greece \\ Email: agoula@uniwa.gr
}

How to cite this paper: Goula, A., Koufioti, G., Kounios, A., \& Sepetis, A. (2020). Occupational Burnout: A Comparison of Field Research of General and Psychiatric Hospitals in Greece after the Financial Crisis. Journal of Human Resource and Sustainability Studies, 8, 419-431.

https://doi.org/10.4236/jhrss.2020.84024

Received: November 1, 2020

Accepted: December 25, 2020

Published: December 28, 2020

Copyright $\odot 2020$ by author(s) and Scientific Research Publishing Inc. This work is licensed under the Creative Commons Attribution International License (CC BY 4.0).

http://creativecommons.org/licenses/by/4.0/

(c) $\underset{\mathrm{By}}{\text { (i) Open Access }}$

\begin{abstract}
At a time when rates, employment demands, insecurity and stress are on the rapidly increasing, exhaustion and stress are becoming an everyday reality for more and more professionals, with detrimental effects on their health, family and professional relationships. The aim of the study is to evaluate statistically significant differences of professionals between general and mental health hospitals. A questionnaire survey was carried out on 128 employees in general health units and 99 employees in mental health units, in Athens, Greece. The results showed statistically significant differences in the variable of personal achievement to a significant level. Employees in mental health units provide a higher average value for this variable than employees in general hospitals. The variable of personal achievement demonstrated statistically significant differences between employees of different age groups, marital status and educational level. Older employees, married employees and lower-level educated employees have been identified to have a higher mean value as a variable of personal achievement. Statistically significant differences were observed in relation to emotional exhaustion factor among employees of different specializations. Nurses, and subsequently physicians, report higher mean values for emotional exhaustion than managers and paramedical employees who report lower mean values for this variable. Enhancing awareness of the phenomenon of occupational burn-out can lead to development of effective intervention measures aimed at improving the well-being of medical and nursing staff, assuring the best possible outcome with the least possible medical risk and optimizing maximum possible health risk of patients.
\end{abstract}

\section{Keywords}

Mental Health Hospitals, Meta-Economic Crisis Period, Occupational 


\section{Introduction}

The term "professional exhaustion" (burnout) was used for the first time in scientific literature in 1974, and so far no definition has been established for this occurrence (Freudenberger, 1974). Nevertheless, amongst the most widely recognized concepts of occupational burnout (OB) is that established by Christina Maslach in 1982 (Maslach, 1982; Leiter \& Maslach, 2004). Maslach identified "a physical and mental exhaustion syndrome in which the employee loses his or her motivation and positive feelings towards his or her patients, ceases to be pleased with his or her work and success and develops a negative image of himself or herself". According to Maslach and Jackson, the three important factors that classify occupational burnout are emotional exhaustion, depersonalization or dissatisfaction and a sense of ineffectiveness (lack of personal achievement) (Maslach \& Jackson, 1984; Maslach \& Jackson, 1986; Leiter, \& Maslach, 2009). Multiple international studies have addressed potential correlations of occupational burnout with work-environmental factors, human influences and personality factors (Duquette et al., 1994; Melchior et al., 1997; Bridgeman et al., 2018). Of the aspects of the working environment correlated with the occupational burnout of medical and nursing staff, those consistently recognized as the most relevant entail workload (Biaggi et al., 2003; Campbell et al., 2001; Gabbe et al., 2002), high-stress levels (Ramirez, et al., 1995; Visser, et al., 2003), the rise of conflicts with colleagues, supervisors or patients' relatives (Fujiwara et al., 2003; Jenkins \& Elliott, 2004), social support provided from colleagues and superiors (Kalliath \& Morris, 2002), job satisfaction (Shanafelt et al., 2002), the equilibria of work-life and personal life (Guntupalli \& Fromm, 1996; Grunfeld et al., 2000), the sense of control and autonomy (Aiken et al., 2002), the sense of purpose and wellbeing (Vahey et al., 2004), the in-person skills (Robinson, 2004), the training of communication skills (Fothergill, et al., 2004) and, of course, the earnings relating to employment (Duquette et al., 1994). Burnout syndrome directly affects health care employees by reducing their employees' satisfaction and increasing their turnover rate, and by triggering psychological symptoms, low morale, and drug and alcohol abuse (Abushaikha \& Saca-Hazboun, 2009; Leiter \& Maslach, 2009; Vahey et al., 2004).

Against the backdrop of the regional and global economic crises, these phenomena have recently increased and worsened. In certain cases, this relentless pressure and stress, may have a positive effect, but in others, it can negatively affect both performance, productivity and, above all, wellbeing, physical and mental health. In recent years, there has been an exponential increase in the prevalence of occupational stress and burn-out, as the implications of the phenomena are increasingly being seen in Greece, either from a technocratic point of view, namely the cost of impacts on service, or from an anthropocentric point of view, 
i.e. studies on the individual and at the level of human relations and the environment (Goula et al., 2017; Goula et al., 2019).

Public sector providers are becoming the primary source of health insurance as revenue for private health services decreases, although government funding revenue is decreasing. When national currencies are depreciated, the cost of import increases. The price of medicines increases significantly which leads to a decrease in the availability of certain medications in the market or that their purchase is prohibitive due to high costs. Whereas overall health expenditure increased from 5.3 per cent of GDP in 1991 to 9.7 per cent in 2008, a percentage point above the OECD average of 8.9 per cent, the Greek health system's effectiveness dropped significantly (Oikonomou \& Mariolis, 2010; Luna, 2011; Simou \& Koutsogeorgou, 2014).

In addition, changes in employment, job insecurity (layoffs, resignations), but also the loss of monthly income (quantitatively but also on a fixed basis), due to economic crisis, are added as additional aggravating factors in the burnout of health care professionals (Depastas \& Pierrakos, 2015).

Mental health professionals play a vital role in providing medical care in the psychiatric hospitalization of patients, as well as in creating opportunities for effective management of potentially dangerous behaviours, with a view to reducing the circumstances that lead to the use of physical restraint and isolation. In the context of the avoidance of deteriorating uncontrolled behaviour, the possible options need to be explored before determining on the use of restrictive measures, which may also generate additional psychological pressures on the part of the health professional themselves, based on the cornerstone of the communication channel they have formed with the patient due to long-term hospitalization (Short et al., 2008; Bigwood \& Crowe, 2008). In addition, the organizational framework for the operation of the psychiatric unit, in particular following the funding cuts in medical systems in Greece in the advent of the financial crisis, could increase the use of restrictive measures, such as inadequate numbers of nursing staff, thereby impacting both patients and staff and undermining the provision of quality care (Pollard, et al., 2007).

\section{Materials and Methods}

The aim of the study is to identify statistically significant differences between personnel in general hospitals and personnel in mental health units in relation to the three dimensions of burnout: emotional fatigue, depersonalization and personal achievement. Similarly, the presence of variations between employees with different demographic characteristics in the three factors of occupational burnout is examined. The research tool used in this survey is the Maslach Burnout Inventory which has been used in a variety of researches to study burnout, including with health professionals.

\subsection{Sampling Methodology}

To the above purpose, a questionnaire survey was carried out in two general 
public hospitals (128 employees responded successfully) and the same questionnaire was distributed to two mental health hospitals (99 employees responded successfully) in Athens, Greece. The survey carried out in January, February 2019.

Regarding the public mental hospitals, the two that exist in the Attica Basin were selected. The selection criterion for the general public hospitals was the broad variety of healthcare facilities they provide and the large number of patients they serve and accommodate on a regular basis.

The research design was cross-sectional, and stratified sampling was the sampling scheme. The stratification process was based on the participants' specialization, so the population was divided into sub-groups that were mutually exclusive (doctors, nurses, administrative and paramedical staff) and then a simple random sampling was applied in each stratum in order to select a random sample of each subgroup.

\subsection{Research Tool-Questionnaire}

The distributed questionnaire consisted of three (3) groups of questions: the first group was composed of questions relating to the personal and demographic data of the respondents; the second group comprised of questions regarding to working conditions; the third group consisted of the Maslach questionnaire, which included 22 sentences and three dimensions of occupational exhaustion: Emotional exhaustion (proposals 1, 2, 3, 6, 8, 13, 14, 16, 20), depersonalization (proposals 5, 10, 11, 15, 22) and personal achievement (proposals 4, 7, 9, 12, 17, $18,19,21)$. The rating is given on a seven-point scale expressing the frequency with which the individual experiences each sentence described: 1) Never 2) Sometimes a year 3) Once a month 4) Sometimes a month 5) Once a week 6) Sometimes a week 7) Every day. After the questionnaires were compiled, the accuracy and completeness of the answers were reviewed and each one of the questionnaires was numbered. The encoding of the questionnaire variables was accompanied by the inclusion of the data in the SPSS statistical software. The data was then analyzed, the three extraction variables were extracted, and the requisite statistical controls were carried out.

\section{Results}

\subsection{The Profile of the Respondents}

The survey included a total of 227 respondents, 99 of whom work in psychiatric hospitals and 128 in general hospitals. Regarding the gender of the survey, 30.1 per cent of the respondents were male, while 69.6 per cent were female. Regarding the age of the respondents, $48.2 \%$ were 20 to 41 years old cumulatively, while $51.8 \%$ were older than 42 years old. As far as marital status is concerned, the largest proportion of respondents was married (63.9\%), while the smallest percentage was single $(21.1 \%)$ and divorced $(10.7 \%)$. At the same time, graduates of Universities or other form of Higher Education represented the largest propor- 
tion of respondents, accompanied by 18.5 per cent of postgraduate or doctoral degrees. Lesser numbers appeared in high school graduates (14.5 per cent) and IEK (Technical Schools in Greece) graduates (10.1 per cent). Subsequently, in terms of the specialization of the respondents, the highest percentage was for nurses (48.6 per cent), while the lowest percentage was for doctors (17.2 per cent), administrative staff (18.9 per cent) or paramedical employees (12.8 per cent) (Table 1 \& Table 2 ).

\subsection{Results of the Survey}

Table 3 presents the main descriptive measures of the three variables of occupational burnout characteristics. At the same time, correlation tests between the three variables were performed. As shown in Table 4, statistically significant correlations between the three variables at $1 \%$ significance level were found. Specifically, depersonalization had a positive correlation with emotional exhaustion $(r=0.439)$, whereas personal achievement had a negative correlation with depersonalization $(r=-0.381)$ and a negative correlation with emotional exhaustion $(r=0.7)$. Subsequently, a series of mean difference tests ( $t$-test and ANOVA-test) were conducted to detect statistically significant differences between employees with different characteristics in the three occupational burnout

Table 1. Allocation of frequencies for demographic data of the responders i.e. sex, age, marital status.

\begin{tabular}{|c|c|c|c|c|c|c|c|c|c|c|c|c|c|c|}
\hline & \multicolumn{3}{|c|}{ Valid sex } & \multicolumn{5}{|c|}{ Valid age } & \multicolumn{6}{|c|}{ Valid marital status } \\
\hline & Male & Female & Missing & $20-30$ & $31-41$ & $42-52$ & $>53$ & Missing & Single & Married & Divorced & In widowhood & $\begin{array}{l}\text { In cohabitation } \\
\text { status }\end{array}$ & Missing \\
\hline Frequency & 68 & 158 & 1 & 30 & 76 & 87 & 27 & 7 & 48 & 145 & 24 & 4 & 4 & 2 \\
\hline Percent & 30.0 & 69.6 & 0.4 & 13.2 & 33.5 & 38.3 & 11.9 & 3.1 & 21.1 & 63.9 & 10.6 & 1.8 & 1.8 & 0.9 \\
\hline Valid percent & 30.1 & 69.6 & & 13.6 & 34.5 & 39.5 & 12.3 & & 21.3 & 64.4 & 10.7 & 1.8 & 1.8 & \\
\hline
\end{tabular}

Table 2. Allocation of frequencies for demographic data of the responders i.e. educational status, specialization.

\begin{tabular}{|c|c|c|c|c|c|c|c|c|c|c|}
\hline & \multicolumn{5}{|c|}{ Valid educational status } & \multicolumn{5}{|c|}{ Valid specialization } \\
\hline & $\begin{array}{c}\text { High } \\
\text { school } \\
\text { graduate }\end{array}$ & $\begin{array}{c}\text { IEK } \\
\text { graduate }\end{array}$ & $\begin{array}{c}\text { Graduate of Universities } \\
\text { or other form of Higher } \\
\text { Education }\end{array}$ & $\begin{array}{c}\text { Postgraduate } \\
\text { or } \mathrm{PhD}\end{array}$ & Missing & Doctor & Nurse & $\begin{array}{l}\text { Administrative } \\
\text { staff }\end{array}$ & $\begin{array}{l}\text { Paramedical } \\
\text { employees }\end{array}$ & Missing \\
\hline Frequency & 33 & 23 & 129 & 42 & 0 & 39 & 105 & 43 & 29 & 11 \\
\hline Valid percent & 14.5 & 10.1 & 56.8 & 18.5 & & 18.1 & 48.6 & 18.9 & 13.4 & \\
\hline
\end{tabular}

Table 3. Descriptive measures of the three characteristics of occupational burnout.

\begin{tabular}{cccccc}
\hline & N & Minimum & Maximum & Mean & Std. Deviation \\
\hline Burnout_depersonalization & 208 & 5 & 30 & 13.19 & 5.909 \\
Burnout_personal achievement & 206 & 20 & 56 & 40.95 & 7.704 \\
Burnout_emotional exhaustion & 214 & 9 & 58 & 33.31 & 11.214 \\
\hline
\end{tabular}


Table 4. Correlation tests between the three characteristics of occupational burnout.

\begin{tabular}{|c|c|c|c|c|}
\hline & & $\begin{array}{c}\text { Burnout__ } \\
\text { depersonalization }\end{array}$ & $\begin{array}{l}\text { Burnout_personal } \\
\text { achievement }\end{array}$ & $\begin{array}{c}\text { Burnout_emotional } \\
\text { exhaustion }\end{array}$ \\
\hline \multirow{3}{*}{$\begin{array}{c}\text { Burnout__ } \\
\text { depersonalization }\end{array}$} & Pearson Correlation & 1 & $-0.381^{\star * *}$ & $0.439^{* * *}$ \\
\hline & Sig. (2-tailed) & & 0.000 & 0.000 \\
\hline & $\mathrm{N}$ & 208 & 201 & 201 \\
\hline \multirow{3}{*}{$\begin{array}{c}\text { Burnout_ } \\
\text { personal } \\
\text { achievement }\end{array}$} & Pearson Correlation & & 1 & $-0.357^{\star * *}$ \\
\hline & Sig. (2-tailed) & & & 0.000 \\
\hline & $\mathrm{N}$ & & 206 & 201 \\
\hline \multirow{3}{*}{$\begin{array}{l}\text { Burnout_ } \\
\text { emotional } \\
\text { exhaustion }\end{array}$} & Pearson Correlation & & & 1 \\
\hline & Sig. (2-tailed) & & & \\
\hline & $\mathrm{N}$ & & & 214 \\
\hline
\end{tabular}

${ }^{* * *} p$-value $<0.01$

factors. Initially the discrepancies between employees in general and mental hospitals in the three occupational burnout variables were investigated.

According to the outcomes of the t-tests, there were no statistically significant differences between employees in general and mental health hospitals in terms of personalization and emotional exhaustion factors. On the contrary, there were statistically significant differences in personal achievement factors at the $1 \%$ level of significance. Explicitly, general hospital employees recorded a higher average value of a personal achievement factor than mental hospital employees. (Table 5) Subsequently, the variations between different genders of the employees in the three occupational burnout factors were investigated. According to the outcomes of the t-tests, there were no statistically significant differences between employees of different sexes with respect to the three occupational burnout factors to any degree of statistical significance.

Reportedly, the variations between employees of different ages in the three occupational burnout factors were reviewed. According to the results of the t-tests, there were no statistically significant differences in impersonal and emotional exhaustion factors between employees of different ages. On the contrary, there were statistically significant differences in personal achievement at the 5\% level of significance. Older employees, in fact, provide a higher average sense of personal achievement than younger employees. Promptly, the variations between employees with different marital status in the three occupational burnout factors were evaluated.

According to the analysis of the t-tests, there were no statistically significant differences in personalization and emotional exhaustion between employees of different marital status. On the contrary, there were statistically significant differences in personal achievement at the 5\% significance level. Married employees, in particular, provide a higher average value of personal achievement than unmarried workers. Subsequently, the disparities between employees with 
Table 5. Hospital type and occupational exhaustion (t-test).

\begin{tabular}{cccccccccc}
\hline & \multicolumn{3}{c}{ Mental health hospitals } & \multicolumn{3}{c}{ General hospitals } & \multicolumn{2}{c}{ t-test } \\
\hline & $\mathrm{N}$ & Mean & Std. Deviation & $\mathrm{N}$ & Mean & Std. Deviation & $\mathrm{t}$ & $p$-value \\
\hline Burnout_depersonalization & 99 & 12.53 & 5.889 & 109 & 13.80 & 5.889 & -1.557 & 0.121 \\
Burnout_personal achievement & 99 & 44.25 & 7.336 & 107 & 37.90 & 6.740 & 6.480 & $0.000^{* * *}$ \\
Burnout_emotional exhaustion & 99 & 33.29 & 10.834 & 115 & 33.33 & 11.578 & -0.024 & 0.981 \\
\hline
\end{tabular}

${ }^{* * *} p$-value $<0.01$.

different educational backgrounds in the three factors of occupational burnout were investigated. According to the analysis of the ANOVA tests there appeared no statistically significant differences between employees at varying levels of education in relation to the factors of personification and emotional exhaustion. On the contrary, there were statistically significant differences in personal achievement at the 5\% level of significance. Explicitly, high school graduates and subsequently IEK graduates provide a higher average value in personal achievement than universities or other form of higher education graduates and postgraduate doctoral holders who have the lowest average value in this variable. Subsequently, the variations between employees with different specializations in the three factors of occupational burnout were examined.

According to the results of the ANOVA tests, no statistically significant differences were found between employees of different specialties, in relation to the factors of impersonation and personal achievement. On the contrary, there were statistically significant differences with regard to the factor of emotional exhaustion to the $5 \%$ significance level. Specifically, nurses, and subsequently physicians, reported higher mean levels of emotional exhaustion than managers and paramedical employees who report the lowest mean values for this factor. (Table 6)

\section{Discussion}

At a time when rates, employment demands, insecurity and stress are on the rapidly increasing, exhaustion and stress are becoming an everyday reality for more and more professionals, with detrimental effects on their health, family and professional relationships (Tennant, 2001).

The aim of the study was to evaluate statistically significant differences of professionals between general hospitals and mental health hospitals in relation to the three dimensions of occupational burnout: emotional exhaustion, depersonalization and personal achievement.

The results showed statistically significant differences in the variable of personal achievement to a significant level. Employees in mental health units provide a higher average value for this variable than employees in general hospitals. At the same time, the variable of personal achievement demonstrated statistically significant differences between employees of different age groups, marital status and educational level. Older employees, married employees and lower-level 
Table 6. Specialty and occupational exhaustion (ANOVA test).

\begin{tabular}{ccccccccccccccccc}
\hline & \multicolumn{3}{c}{ Doctor } & & \multicolumn{2}{c}{ Nurse } & & \multicolumn{2}{c}{ Administrative staff } & Paramedical employees & ANOVA-test \\
\hline & $\mathrm{N}$ & Mean & $\begin{array}{c}\text { Std. } \\
\text { Deviation }\end{array}$ & $\mathrm{N}$ & $\begin{array}{c}\text { Mean } \\
\text { Deviation }\end{array}$ & $\begin{array}{c}\text { Std. } \\
\text { Devition }\end{array}$ & $\begin{array}{c}\text { Mean } \\
\text { Deviation }\end{array}$ & N & $\begin{array}{c}\text { Mean } \\
\text { Deviation }\end{array}$ & F & $p$-value \\
\hline Burnout_depersonalization & 37 & 12.97 & 5.689 & 103 & 13.33 & 5.823 & 29 & 13.55 & 6.390 & 29 & 13.10 & 6.108 & 0.064 & 0.979 \\
Burnout_personal achievement & 39 & 39.36 & 7.140 & 102 & 41.67 & 7.325 & 30 & 40.03 & 9.866 & 26 & 41.65 & 7.515 & 1.050 & 0.372 \\
Burnout_emotional exhaustion & 38 & 34.50 & 12.004 & 102 & 35.05 & 10.545 & 37 & 32.89 & 11.951 & 28 & 27.64 & 10.418 & 3.418 & $0.018^{* *}$ \\
\hline
\end{tabular}

${ }^{* *} p$-value $<0.05$.

educated employees have been identified to have a higher mean value as a variable of personal achievement. Gradually, statistically significant differences were observed in relation to the emotional exhaustion factor among employees of different specializations. In particular, nurses and, subsequently physicians, reported higher mean values for emotional exhaustion than managers and paramedical employees who reported lower mean values for this variable.

The above observations are in accordance with Ivancenich and Matteson (Cooper et al., 1988), who suggest that when employees feel high levels of stress at work, they indeed experience high rates of both job dissatisfaction and workplace burnout. Dimitropoulos \& Filippou (2008) also document that occupational stress is characterized by occupational exhaustion. These concerns extend from the perception of the specialty of mental health hospitals, especially stressful interactions with patients and challenging relations with other mental health providers as part of interdisciplinary teams, to the personal threats posed by abusive patients (Rossler, 2012).

In the study of Naisberg-Fennig et al., forty-nine mental health professionals, residents and specialists from three hospitals were involved. Personality traits chosen were: repression-sensitization (RS), anxiety condition (AS) and learning resourcefulness (LR), age, duration at work, time at work, marital status and home country were also documented. Occupational burnout was noticed to be profoundly related to AS and RS and harshly related to LR (Naisberg-Fennig et al., 1991). The effect of occupational burnout of nurses on patient satisfaction with the care provided was also reported in research by Vahey et al. In this study, occupational exhaustion of nurses, determined on the basis of the scale of emotional exhaustion and lack of personal accomplishment, was an important factor in patients' satisfaction regarding nursing care (Valey, et al., 2004).

Kalogeropoulou \& Papathanasopoulou (2013) reviewed nurses in three hospitals in Athens in 2013, where it was observed that the financial crisis had had a major impact on their work making them vulnerable. In 2015, Nanou et al., conducted research in public and private hospitals in Athens, where it was observed that public sector nursing staff seemed to have higher levels of occupational burnout than in the private sector. A recent analysis in Greece indicates that the shortage of medical supplies during the financial crisis was aligned with emotional exhaustion and deprivation of health professionals. It is therefore 
known that extreme austerity in Greece has weakened healthcare in terms of quality and increasing work-related stress (Saridi, et al., 2016). Priebe et al., in a recent study directed at determining factors predicting the outcome of psychiatric patients diagnosed with positive treatment in response, found that staff involvement and personal achievement were associated with patients' health outcomes (Priebe et al., 2004).

There is no distinction in the area of mental health from other healthcare specialties. Health care professionals need to evaluate and incorporate knowledge and practice to help patients improve. It is worth mentioning that treatment is not only focused on biological or psychological needs, but at the same time contributes to both. Apparently, a person's body is not isolated from their mind and their mental health reflects on these two elements (Nicavio et al., 2018). It is the mental health nurse who occupies a leading role in patient care in psychiatric units. The mental health professional performs more than one role in these units. They must first identify the problem, evaluate it, and then provide interventions that will yield the correct results to resolve it (Koukia \& Gonis, 2010). Communication with the patient, collaboration, teamwork and organization are another essential part of their job description. In addition, the nurse needs to deal and adapt effectively to the changes occurring in the treatment plan, based on advances in the care of patients recovering from illness.

Health care professionals dealing with patients with special needs concerning their mental stability experience specific stressors that do not support their personal well-being and professional efficiency. Health professionals should focus on establishing a therapeutic alliance for the benefit of the patient (Heightman, 2014). Factors that overwhelm psychiatric care professionals and often cause burn-out syndrome are job frustration, difficulties in working relationships between personnel, lack of communication and interaction with patients and families, heavy workloads, reduced staff and diminished support or incentives from senior managers.

Comprehending these variables and assessing all the criteria of this particular area of medical practice, such as risk and violence makes it easier for mental health professionals to improve their working conditions and thus benefit from quality patient care (Sobekwa, 2015; Conradie et al., 2017). In accordance with the bibliographic data, the research indicates the pressure on mental health professionals on the basis of their working conditions. Nonetheless, the most important parameter to consider is that occupational exhaustion syndrome, and in particular the depersonalization and loss of personal accomplishment of these health professionals, has a higher statistical effect due to their interaction with the patient and the complexity of the hospitalization. In accordance with our results, a study of eleven short-term care units of two psychiatric facilities in Athens and the wider area was performed in 2010.

The objective of this study was to record the most critical clinical problems that nurses face on a daily basis. 100 per cent of the study suggested that the most significant health issue was the lack of staff. The responders have reported 
that due to a lack of resources, the time they provide for each patient was reduced. As a consequence, contact between the nurse-patient is lost and therefore the therapeutic impact is impaired (Koukia \& Gonis, 2010).

In this context, the management of each organization should explain the position and duties of each individual in their decision-making, since interdisciplinary cooperation between health and social care practitioners is a dynamic process that requires them to function properly and to clarify responsibilities (Zarei et al., 2016). In particular, for situations where health and social care professionals deal with serious events, rest and extended breaks should be available (Goula, 2007). The consequences of the economic crisis on overall health are not plainly obvious and seem to fluctuate wildly, as it is a multi-factorial phenomenon and should, therefore, be viewed with great attention (Madianos et al., 2011).

\section{Conclusion}

The results of this study indicate that occupational burnout may be differentiated in means of statistical outcomes between general and mental hospitals. Moreover, higher occupational burnout outcomes are more likely to be associated with the variables of age, sex and marital status. Enhancing awareness of the phenomenon of occupational burn-out can lead to the development of effective intervention measures aimed at improving the well-being of medical and nursing staff, assuring the best possible outcome with the least possible medical risk and optimizing the maximum possible health benefit of the patient from the care provided.

\section{Acknowledgements}

This study has been done within the framework of the Postgraduate Health and Social Care Management Programme of the University of West Attica.

\section{Conflicts of Interest}

The authors declare no conflicts of interest regarding the publication of this paper.

\section{References}

Abushaikha, L., \& Saca-Hazboun, H. (2009). Job Satisfaction and Burnout among Palestinian Nurses. Eastern Mediterranean Health Journal, 15, 190-197. https://pubmed.ncbi.nlm.nih.gov/19469443 https://doi.org/10.26719/2009.15.1.190

Aiken, L., Clarke, S., \& Sloane, D. (2002). Hospital Staffing, Organization, and Quality of Care: Cross-National Findings. International Journal for Quality in Health Care, 14, 5-13. https://doi.org/10.1093/intqhc/14.1.5

Biaggi, P., Peter, S., \& Ulich, E. (2003). Stressors, Emotional Exhaustion and Aversion to Patients in Residents and Chief Residents-What Can Be Done? Swiss Medical Weekly, 133, 339-346. 
Bigwood, S., \& Crowe M. (2008). It's Part of the Job, But It Spoils the Job: A Phenomenological Study of Physical Restraint. International Journal of Mental Health Nursing, 17, 215-222. https://doi.org/10.1111/j.1447-0349.2008.00526.x

Bridgeman, P., Bridgeman, M., \& Barone, J. (2018). Burnout Syndrome among Healthcare Professionals. American Journal of Health-System Pharmacy, 75, 147-152. https://doi.org/10.2146/ajhp170460

Campbell, D., Sonnad, S., Eckhauser, E., Campbell, K., \& Greenfield, L. (2001). Burnout among American Surgeons. Surgery, 130, 696-705. https://doi.org/10.1067/msy.2001.116676

Conradie, M., Erwee, D., Serfontein, I., Visser, M., Calitz, F., \& Joubert, G. (2017). A Profile of Perceived Stress Factors among Nursing Staff Working with Intellectually Disabled In-Patients at the Free State Psychiatric Complex. AOSIS, 40, 1578.

http://www.scielo.org.za/pdf/cura/v40n1/02.pdf

https://doi.org/10.4102/curationis.v40i1.1578

Cooper, C., Cooper, R., \& Eaker, L. (1988). Living with Stress. London: Penguin Books.

Depastas, C., \& Pierrakos, G. (2015). The Mental Health of Mental Health Professionals of Non-Governmental Organizations in the National Program "Psychargos": The Effects of the Economic Crisis. Archives of Hellenic Medicine, 32, 758-765. http://www.mednet.gr/archives/2015-6/pdf/758.pdf

Dimitropoulos, H., \& Filippou, N. (2008). Professional Burnout in the Field of Health. Archives of Hellenic Medicine, 25, 642-647. http://www.mednet.gr/archives/2008-5/pdf/642.pdf

Duquette, A., Kerouac, S., Sandhu, B., \& Beaudet, L. (1994). Factors Related to Nursing Burnout: A Review of Empirical Knowledge. Issues in Mental Health Nursing, 15, 337-358. https://doi.org/10.3109/01612849409006913

Fothergill, A., Edwards, D., \& Burnard, P. (2004). Stress, Burnout, Coping and Stress Management in Psychiatrists: Findings from a Systematic Review. International Journal of Social Psychiatry, 50, 54-65. https://doi.org/10.1177/0020764004040953

Freudenberger, H. (1974). Staff Burnout. Journal of Social Issues, 30, 159-165. https://doi.org/10.1111/j.1540-4560.1974.tb00706.x

Fujiwara, K., Tsukishima, E., Tsutsumi, A., Kawakami, N., \& Kishi, R. (2003). Interpersonal Conflict, Social Support, and Burnout among Home Care Workers in Japan. Journal of Occupational Health, 45, 313-320. https://doi.org/10.1539/joh.45.313

Gabbe, S., Melville, J., Mandel, L., \& Walker, E. (2002). Burnout in Chairs of Obstetrics and Gynaecology: Diagnosis, Treatment, and Prevention. American Journal of Obstetrics and Gynecology, 186, 601-612. https://doi.org/10.1067/mob.2002.122391

Goula, A. (2007). Hospital Administration and Management: The Greek Experience and Practice (88 p.). Athens: Papazisis Publications.

Goula, A. et al. (2019). Analysis of the Relationship between Transformational Leadership and Learning Organization in Health Care Services. In Economics SPiBa (Ed.), Strategic Innovative Marketing and Tourism (pp. 155-163). Berlin: Springer.

https://doi.org/10.1007/978-3-030-12453-3 18

Goula, A., Giannopoulou, V., Magouli, P., Ntakou, M., \& Yfantopoulos, N. (2017). Investigation of the Sociomedical Infrastructure for Health Needs Coverage in Periods of Economic Crisis. Archives of Hellenic Medicine, 34, 91-99.

http://www.mednet.gr/archives/2017-1/pdf/91.pdf

Grunfeld, E., Whelan, T., Zitzelsberger, L., Willan, A., Montesanto, B., \& Evans, W. (2000). Cancer Care Workers in Ontario: Prevalence of Burnout, Job Stress and Job Sa- 
tisfaction. Canadian Medical Association Journal, 163, 166-169.

https://pubmed.ncbi.nlm.nih.gov/10934978

Guntupalli, K., \& Fromm, R. (1996). Burnout in the Internist-Intensivist. Intensive Care Medicine, 22, 625-630. https://doi.org/10.1007/BF01709737

Heightman, L. (2014). Origins of Clinician Bias against People Diagnosed with Borderline Personality Disorder. Northampton: Smith College. https://scholarworks.smith.edu/cgi/viewcontent.cgi?article=1879\&context=theses

Jenkins, R., \& Elliott, P. (2004). Stressors, Burnout and Social Support: Nurses in Acute Mental Health Settings. Journal of Advanced Nursing, 48, 622-631. https://doi.org/10.1111/j.1365-2648.2004.03240.x

Kalliath, T., \& Morris, R. (2002). Job Satisfaction among Nurses. A Predictor of Burnout Levels. JONA: The Journal of Nursing Administration, 32, 648-654. https://doi.org/10.1097/00005110-200212000-00010

Kalogeropoulou, M., \& Papathanassopoulou, E. (2013). The Impact of the Financial Crisis on the Mental Health of Nursing Staff. Pilot Study. Archives of Hellenic Medicine, 5, 587-594. http://www.mednet.gr/archives/2013-5/pdf/587.pdf

Koukia, E., \& Gonis, N. (2010). Training Needs and the Role Limitations of Nursing Staff Working in Short-Term Care Units in Psychiatric Hospitals. The Step of Asclepius, 9, 344-358. http://ejournals.teiath.gr/index.php/tovima/article/view/215

Leiter, M. P., \& Maslach, C. (2004). Areas of Worklife: A Structured Approach to Organizational Predictors of Job Burnout. In P. Perrewé, \& D. C. Ganster (Eds.), Emotional and Physiological Processes and Positive Intervention Strategies (Vol. 3, pp. 91-134). Oxford: Elsevier. https://doi.org/10.1016/S1479-3555(03)03003-8

Leiter, M., \& Maslach, C. (2009). Nurse Turnover: The Mediating Role of the Nursing Work Index. Journal of Nursing Management, 17, 331-339. https://doi.org/10.1111/j.1365-2834.2009.01004.x

Luna, P. (2011). Is the Economic Crisis Affecting the Quality of Neurological Services? The Lancet, 10, 602-603. https://doi.org/10.1016/S1474-4422(11)70133-8

Madianos, M., Economou, M., Alexiou, T., \& Stefanis C. (2011). Depression and Economic Hardship across Greece in 2008 and 2009: Two Cross-Sectional Surveys Nationwide. Social Psychiatry and Psychiatric Epidemiology, 46, 943-952. https://doi.org/10.1007/s00127-010-0265-4

Maslach, C. (1982). Burnout: The Cost of Caring (pp. 1-24). Englewood Cliffs, NJ: Prentice-Hall. https://malorbooks.com/pdf/Burnout preview.pdf

Maslach, C., \& Jackson, S. (1984). Burnout in Organizational Settings. Applied Social Psychology Annual, 5, 133-153.

Maslach, C., \& Jackson, S. (1986). Burnout Inventory Manual (2nd ed.). Palo Alto, CA: Press CP.

Melchior, M., Bours, G., Schmitz, P., Wittich, Y., \& Bours, G. (1997). Burnout in Psychiatric Nursing: A Meta-Analysis of Related Variables. Journal of Psychiatric and Mental Health Nursing, 4, 193-201. https://doi.org/10.1046/j.1365-2850.1997.00057.x

Naisberg-Fennig, S., Fennig, S., Keinan, G., \& Elizur, A. (1991). Personality Characteristics and Proneness to Burnout: A Study among Psychiatrists. Stress Medicine, 7, 201-205. https://doi.org/10.1002/smi.2460070402

Nanou, C., Gourounti, K., Palaska, E., Mallidou, A., \& Sarantaki, A. (2015). Occupational Midwives Working in a Neonatal Intensive Care Unit. Postoperative Nursing, 4, 138-151. https://www.spnj.gr/articlefiles/volume4 issue3/pn september 138 151.pdf

Nicavio, R. T., Toledo, V. P., \& Garcia, A. (2018). From Alienation to the Nursing Clinic: 
Care of Patients. Revista Brasileira de Enfermagem, 71, 2229-2236. https://doi.org/10.1590/0034-7167-2017-0930

Oikonomou, N., \& Mariolis, A. (2010). How Is Greece Conforming to Alma Ata's Principles in the Middle of Its Biggest Financial Crisis? British Journal of General Practice, 60, 456-457. https://doi.org/10.3399/bjgp10X509711

Pollard, R., Yanasak, E., Rogers, S., \& Tapp, A. (2007). Organizational and Unit Factors Contributing to Reduction in the Use of Seclusion and Restraint Procedures on an Acute Psychiatric Inpatient Unit. Psychiatric Quarterly, 78, 73-81. https://doi.org/10.1007/s11126-006-9028-5

Priebe, S., Fakhoury, W., White, I., Watts, J., Bebbington, P., Billings, J. et al. (2004). Characteristics of Teams, Staff and Patients: Associations with Outcome of Patients in Assertive Outreach. British Journal of Psychiatry, 185, 306-311.

https://doi.org/10.1192/bjp.185.4.306

Ramirez, A., Graham, J., Richards, M. et al. (1995). Burnout and Psychiatric Disorder among Cancer Clinicians. British Journal of Cancer, 71, 1263-1269. https://doi.org/10.1038/bjc.1995.244

Robinson, G. (2004). Career Satisfaction in Female Physicians. JAMA, 291, 635. https://doi.org/10.1001/jama.291.5.635

Rossler, W. (2012). Stress, Burnout, and Job Dissatisfaction in Mental Health Workers. European Archives of Psychiatry and Clinical Neuroscience, 262, 65-69. https://doi.org/10.1007/s00406-012-0353-4

Saridi, M., Karra, A., \& Souliotis, K. (2016). Occupational Stress and Health Professionals in Times of Financial Crisis. Archives of Hellenic Medicine, 33, 73-83. http://www.mednet.gr/archives/2016-1/pdf/73.pdf

Shanafelt, T., Bradley, K., Wipf, J., \& Back, A. (2002). Burnout and Self-Reported Patient Care in an Internal Medicine Residency Program. Annals of Internal Medicine, 136, 358-367. https://doi.org/10.7326/0003-4819-136-5-200203050-00008

Short, R., Sherman, M., Raia, J., Bumgardner, C., Chambers, A., \& Lofton, V. (2008). Safety Guidelines for Injury-Free Management of Psychiatric Inpatients in Precrisis and Crisis Situations. Psychiatric Service, 59, 1376-1378.

https://doi.org/10.1176/ps.2008.59.12.1376

Simou, E., \& Koutsogeorgou, E. (2014). Effects of the Economic Crisis on Health and Healthcare in Greece in the Literature from 2009 to 2013: A Systematic Review. Health Policy, 115, 111-119. https://doi.org/10.1016/j.healthpol.2014.02.002

Sobekwa, Z. (2015). Experiences of Nurses Caring for Mental Health Care Users in an Acute Admission Unit at a Psychiatric Hospital in the Western Cape Province. AOSIS, 38, 1059. https://core.ac.uk/download/pdf/62636191.pdf https://doi.org/10.4102/curationis.v38i2.1509

Tennant, C. (2001). Work-Related Stress and Depressive Disorders. Journal of Psychosomatic Research, 51, 697-704. https://doi.org/10.1016/S0022-3999(01)00255-0

Vahey, D., Aiken, L., Sloane, D., Clarke, S., \& Vargas, D. (2004). Nurse Burnout and Patient Satisfaction. Medical Care, 42, II57-II66. https://doi.org/10.1097/01.mlr.0000109126.50398.5a

Visser, M., Smets, E., Oort, F., \& De Haes, H. (2003). Stress, Satisfaction and Burnout among Dutch Medical Specialists. Canadian Medical Association Journal, 168, 271-275.

Zarei, E., Khakzad, N., Reniers, G., \& Akbari, R. (2016). On the Relationship between Safety Climate and Occupational Burnout in Healthcare Organizations. Safety Science, 89, 1-10. https://doi.org/10.1016/j.ssci.2016.05.011 